\title{
Procedure Agents Supplemental Qualifiers Dataset
}

National Cancer Institute

\section{Source}

National Cancer Institute. Procedure Agents Supplemental Qualifiers Dataset. NCI

Thesaurus. Code C147186.

A dataset containing supplemental information, specifically non-standard variables, to parent records in the procedure agents domain. 